\title{
Hemodynamic Effects of Concentric and Eccentric Outflow Graft of LVADs on the Aortic Valve
}

\section{Zhiming Song}

Shanghai East Hospital https://orcid.org/0000-0002-1762-9177

\section{Lufeng Zhang}

Peking University Third Hospital

\section{Yagang Ding}

Shanghai East Hospital

\section{Qing Wan}

Shanghai East Hospital

\section{Yunzhen Feng}

Shanghai East Hospital

\section{Heqing Wang}

Shanghai East Hospital

\section{Guoliang Fan}

Shanghai East Hospital

\section{Yangyang Zhang}

Shanghai East Hospital

Feng Wan ( $\nabla$ drwanfengvip@126.com )

\section{Research}

Keywords: smoothed particle hydrodynamics, aortic insufficiency, fluid-structure interaction, hemodynamics, biomechanics

Posted Date: August 3rd, 2020

DOI: https://doi.org/10.21203/rs.3.rs-48862/v1

License: (c) (1) This work is licensed under a Creative Commons Attribution 4.0 International License. Read Full License 


\section{Title page}

1.The title:Hemodynamic Effects of Concentric and Eccentric Outflow Graft of LVADs on the Aortic Valve

\section{Author:}

Zhiming Song,MD ${ }^{\#, a}$; Lufeng Zhang,MD ${ }^{\#, c}$; Yagang Ding,MD ${ }^{\#, a}$; Qing Wan,MD Yunzhen Feng,MD ${ }^{\mathrm{a}}$; Heqing Wang,MD ${ }^{\mathrm{a}}$; Guoliang Fan, MD*,a; Yangyang

Zhang,MD*,a; Feng Wan,MD*,a

\# Co First author,${ }^{*}$ Co Corresponding author,

a Department of Cardiac Surgery, Shanghai East Hospital, Tongji University

School of Medicine, China.

b Department of Cardiovascular Medicine, Shanghai East Hospital, Tongji

University School of Medicine, China.

c Department of Cardiac Surgery, Peking Unviersity Third Hospital, China

3.Corresponding author: Feng Wan, Yangyang Zhang, Guoliang Fan

For reprints and all correspondence: Feng Wan

No. 150 Ji Mo Rd, Shanghai 200120,China.

postal code: 200120

Email: drwanfengvip@126.com 


\begin{abstract}
Background: Aortic valve disease is a common complication of left ventricular assist device (LVAD) support. Optimizing the outflow graft anastomotic type of LVADs might be an alternative that can reduce this complication. However, the effect of this type of LVAD on the biomechanical states of the aortic valve remains unclear.
\end{abstract}

Methods: In this study, a finite element-smoothed particle hydrodynamics-coupled model was established. Two kinds of anastomotic types (concentric and eccentric graft cases) were designed.

Results: The anastomotic type could significantly affect the biomechanical states of the aortic valve. During the opening phase, the motion, deformation, and biomechanical states of the leaflet in both cases were similar to each other. The axial hemodynamic force (AHF) imposed on the leaflet in the eccentric graft case $(0.9 \mathrm{~N})$ was slightly larger than that in the concentric graft case $(0.3 \mathrm{~N})$. During the closing phase, the rapid closing time of the leaflet in the eccentric graft case (40 ms) was longer than that in the concentric graft case $(15 \mathrm{~ms})$. In addition, the peak value of the AHF in the concentric graft case was much larger $(13 \mathrm{~N})$ than that in the eccentric graft case (4.5 N). The oscillation of the AHF was observed only in the concentric graft case.

Conclusions: The eccentric graft could lead to better biomechanical and hemodynamic states of the aortic valve than the concentric graft.

Keywords: smoothed particle hydrodynamics, aortic insufficiency, fluid-structure interaction, hemodynamics, biomechanics 


\section{Background}

Heart failure is a severe cardiac disease [1]. Left ventricular assist devices (LVADs) have gradually become an important alternative treatment for patients with heart failure to prolong their survival rate and improve their quality of life [2]. Considering the wide use of LVADs in clinical practice, complications in the aortic valve caused by LVAD support are attracting an increasing amount of attention. Jorde et al. and Gasparovic et al. reported that aortic insufficiency is a common complication in patients with LVADs and requires surgical correction [3,4]. Similarly, Stephens et al. reported that the aortic valves in patients with LVAD showed decreased compliance and increased expression of numerous proteins related to valve activation and injury compared with patients without LVAD [5]. Many studies have been conducted to reduce the incidence of aortic valve disease. Zhang et al. studied the stress distribution on the aortic leaflet under different LVAD support conditions via the finite element (FE) method [6]. Their results demonstrated the positive relationship between the LVAD support level and the stress imposed on the aortic valve and that the reduction in LVAD support level might beneficial for preventing aortic valve disease. Karmonik et al. investigated the effect of the orientation of LVAD outflow graft on aortic insufficiency. Their results demonstrated that an LVAD outflow graft should be placed to aim the jet of blood toward the lumen of the aortic arch, reducing the retrograde pressure in the aortic valve [7]. Similarly, Zhang et al. reported that the LVAD outflow graft location could significantly influence the hemodynamic states of the ascending aorta [8]. Moreover, the hemodynamic states in the ascending aorta could be improved by introducing the 
helical flow component of LVAD outflow into the aorta [9]. Although these studies provided useful information, the effect of the LVAD outflow graft anastomotic type on the biomechanical states of the aortic valve remains unclear. E present work is to clarify this imortaant issue, using an original emethodology.

Two kinds of outflow graft anastomotic type, namely, the "concentric graft" and the “eccentric graft," exist in clinical vascular surgery. The concentric graft [10], in which the axis of the graft vessel intersects with the axis of the aorta, has been widely used in LVAD implantation [11]. The eccentric graft, in which the axis of the graft vessel is not coplanar with the aortic axis, has also been studied by many researchers. Sun et al. investigated the hemodynamic effect of the eccentric graft on the artery [12]. They demonstrated that the eccentric graft could enhance the wall shear stress in the artery. Wen et al. reported that compared with the concentric graft, the eccentric graft could improve flow behavior at the distal anastomosis [13]. Moreover, Liu demonstrated that the eccentric graft could generate helical blood flow, which benefits the structure and function of the artery [14]. The present study determined whether the eccentric graft type generates better hemodynamic states to the aortic valve due to its several advantages compared with the concentric graft type.

Computational analysis is an important method widely utilized to study the biomechanic state of the aortic valve. Many decoupled FE and computational fluid dynamic (CFD) methods are commonly used to investigate the aortic leaflet dynamics [15]. However, the structural and hemodynamic responses of the aortic valve could not be calculated using both approaches due to the strong coupling effects between the 
blood and flexible leaflets. The fluid-structure interaction (FSI) approach is being actively pursued at present [16]. Chandra et al. compared the differences in wall shear stress between the bicuspid aortic valve and tricuspid aortic valve using the $2 \mathrm{D}$ arbitrary Lagrangian-Eulerian (ALE) approach [17]. Using the same approach, Wald et al. presented a numerical study that examined the impact of severe aortic stenosis and transcatheter aortic valve implantation on coronary blood flow under rest conditions [18]. However, the ALE method has only been successfully applied to the 2D model and not to the 3D model [19]. Subsequently, Fedele et al. proposed a resistive immersed implicit surface (RIIS) model for blood flow simulation in the aortic root and aorta that included the movement of the valve leaflets [20]. Although most of these FSI approaches were mesh-based methods, several limitations, including mesh remeshing, numerical instability, and the challenges of aortic valve closing, still exist.

The use of a mesh-free approach as a solution to these problems was considered. This approach is called the smoothed particle hydrodynamic (SPH) method [21]. It is a meshless, Lagrangian particle-based method in which the blood is discretized as a set of particles without the need for a spatial mesh [22]. The SPH approach has been gradually applied to the evaluation of the dynamic and biomechanical properties of the aortic valve $[23 ; 24 ; 25 ; 26 ; 27]$.

In this study, we established an FE-SPH-coupled model to investigate the hemodynamic effect of the concentric and eccentric outflow grafts of LVADs on the hemodynamic states of the aortic valve. The FE model of the aortic valve was coupled with the SPH model, which illustrated the blood flow pattern. The dynamic 
characteristics, stress and strain distributions, and blood flow pattern were calculated to investigate the different effects of concentric and eccentric outflow grafts on the aortic valve.

\section{Results}

The aortic insufficiency was observed at $170 \mathrm{~ms}$ in the concentric graft model, and the results from $0 \mathrm{~ms}$ to $195 \mathrm{~ms}$ were obtained to investigate the hemodynamic difference.

\section{Kinematic characteristics of the leaflet}

The kinematic characteristics of the leaflet under concentric and eccentric graft cases were evaluated based on the time-dependent deformed shape of the middle line of the leaflet (Figure 2, red line). Figures 2 A and B illustrate the deformed shapes of the leaflet under concentric and eccentric graft cases, respectively. The blue and red curves indicated the deformed shape of the leaflet during the opening and closing phases, respectively. At $0 \mathrm{~ms}$, the leaflet under both cases started to open from the same initial position. At the beginning of the opening phase, the leaflet started to deform at the belly region of the leaflet, and then the deformed shape expanded toward the leaflet free edge at $25 \mathrm{~ms}$. This result was consistent with that of a previous study [Mao et al. 2016]. At $55 \mathrm{~ms}$, the leaflet in both cases arrived at the maximum opening position. During the opening phase, the deformed shape of the leaflet under the concentric graft case was similar to that under the eccentric graft case. By contrast, the deformed shape of the leaflet under the concentric graft case considerably differed from that under the eccentric graft case during the closing phase. The closing speed of the leaflet under the 
concentric graft case was much higher than that under the eccentric graft case. The coaptations of the leaflet under concentric and eccentric graft cases occurred at 120 and $155 \mathrm{~ms}$, respectively. At $170 \mathrm{~ms}$, the leaflets under the eccentric graft case were fully closed, whereas an obvious aortic insufficiency was observed under the concentric graft case.

As shown in Figure 3, aside from the deformed shape of the leaflet, the axial hemodynamic force imposed on the leaflet and the radial position of the middle point of the leaflet free edge under both cases were also calculated to compare the difference in the kinematic characteristics of the leaflet. Figure $3 \mathbf{A}$ illustrates the variation in the radial position of the middle point of the leaflet free edge. During the opening phase, the motion of the leaflet under the concentric graft case was quite similar to that under the eccentric graft case. The only difference between them was the maximum radial position, which was related to the geometric orifice area (GOA). The maximum radial position under the concentric graft case was slightly larger than that under the eccentric graft case (concentric graft case vs. eccentric graft case, $7 \mathrm{~mm}$ vs. $6.5 \mathrm{~mm}$ ). In addition, the rapid valve opening and closing time were calculated based on the radial position, which had high positive and negative slopes, according to reference 28 . For concentric graft case, the rapid valve opening and closing time were 22 and $15 \mathrm{~ms}$, respectively. For the eccentric graft case, the rapid valve opening and closing times were 30 and 40 $\mathrm{ms}$, respectively. The time-dependent variation of axial hemodynamic force imposed on the leaflet was illustrated in Figure 3B. The axial hemodynamic force was related to the transvalvular pressure gradient of the aortic valve. In systole, the axial 
hemodynamic force under the eccentric graft case was larger than that under the concentric graft case. The peak values of the axial hemodynamic force under the concentric and eccentric graft cases were 0.3 and $0.9 \mathrm{~N}$, respectively. During the closing phase, large oscillations were observed in the concentric graft case. In addition, the value of the axial hemodynamic force in the concentric graft case was much larger than that obtained in the eccentric graft case (peak value: concentric graft case vs. eccentric graft case, $13 \mathrm{~N}$ vs. $4.5 \mathrm{~N})$.

\section{The distribution of stress and strain}

Figures 4 and $\mathbf{5}$ show the distribution of the stress and strain on the leaflet during the systolic period. Similar distributions of stress and strain on the leaflet were observed during the opening phase, comparing the concentric graft case and eccentric graft case. The peak value of stress was observed along the attachment line of the leaflet under both cases at $55 \mathrm{~ms}$ (concentric graft case vs. eccentric graft case, $0.4 \mathrm{MPa}$ vs. 0.44 $\mathrm{MPa}$ ). In addition, the peak value of strain was observed in the commissure region of the leaflet, whereas the minimum value of the strain was seen at the belly region. The distribution of the stress and strain of the leaflet during the systolic phase was similar to those shown in Mao's study [Mao et al. 2016] as shown in Figures 9 and 10. When the aortic valve was fully opened, high-stress regions were observed at leaflet commissures in our results and those in Mao's study.

The stress and strain distributions on the leaflet during the diastolic period are illustrated in Figures 6 and 7. In contrast with the distribution during the systolic phase, the stress and strain distributions under the concentric graft case considerably differed 
from those under the eccentric graft case. Figure 6 demonstrates the contour curve of the maximum principal stress on the leaflet. The stress value in the concentric graft case was much larger than that in the eccentric graft case. Under the concentric graft case, the peak value of the stress was observed at $155 \mathrm{~ms}$ (approximately $2.4 \mathrm{MPa}$ ), and the maximum stress was mainly concentrated in the commissure regions. At $170 \mathrm{~ms}$, evident aortic regurgitation was observed in the concentric graft case. The maximum stress region in the concentric graft case was moved from the commissure region to the belly region of the leaflet, whereas the stress value was significantly reduced (155 ms, 2.4 MPa vs. $170 \mathrm{~ms}, 0.6 \mathrm{MPa}$ ). By contrast, the peak value of the stress in the eccentric graft case was $170 \mathrm{~ms}$ (approximately $0.8 \mathrm{MPa}$ ), and the region of the peak stress was concentrated in the commissure region.

Figure 7 shows the distribution of the true strain on the leaflet. The maximum values of the strain in both cases were mainly concentrated in the belly region of the leaflet. In the concentric graft case, the peak value of the strain was seen at $155 \mathrm{~ms}$ (approximately $0.8 \mathrm{MPa}$ ). At $170 \mathrm{~ms}$, the maximum strain of the leaflet was moved from the belly region to the free edge due to aortic insufficiency. In addition, the maximum value of the strain was observed under fully closed conditions ( $170 \mathrm{~ms}, 0.65$ MPA) in the eccentric graft case.

The strain and stress distributions during the diastolic phase in this study were also compared with those in Mao's study, and both results were similar. However, the strain and stress values of the leaflet in our study during the diastolic phase was larger than those in Mao's work due to LVAD support, which enhanced the pressure load of the 
leaflet during the diastolic phase. This finding is an important reason for the phenomenon in which the LVAD support could result in aortic valve regurgitation.

Flow pattern of concentric and eccentric graft cases

Flow pattern was evaluated based on the blood velocity contour and vector curve on a cross section through the symmetry plane of the model at four instances (Figures 8 and 9). Figure 8 illustrates the distribution of the blood velocity contour under both cases. During the systolic phase, the forward flows that jetted from the aortic valve and LVAD outflow graft was received at the downstream of the aortic valve (30 and $55 \mathrm{~ms}$, respectively). Evident reverse blood flow was observed in the concentric graft case (100 $\mathrm{ms}$ ) at the beginning of the diastolic phase, whereas the velocity of the blood flowing toward the left ventricle was significantly smaller in the eccentric graft case $(0.3 \mathrm{~m} / \mathrm{s})$ than in the concentric graft case $(0.8 \mathrm{~m} / \mathrm{s})$. At $170 \mathrm{~ms}$, evident reverse blood flow was also observed in the concentric graft case (the maximum reverse blood velocity was approximately $1.8 \mathrm{~m} / \mathrm{s}$ ). For the eccentric graft case, the blood velocity in the ascending aorta was approximately $0 \mathrm{~m} / \mathrm{s}$, indicating that the aortic valve was fully closed.

Figure 9 shows the blood velocity vector of both cases. The blood flow pattern in the ascending aorta under the concentric graft case considerably differed from that under the eccentric graft case. During the systolic phase, an evident helical flow characteristic was observed in the ascending aorta under the eccentric graft case (red arrow $\mathrm{t}=55 \mathrm{~ms}$ ), whereas the blood flow under the concentric graft flow was parallel to the axis of the ascending aorta $(\mathrm{t}=55 \mathrm{~ms})$. At the beginning of the diastolic phase, vorticity was identified near the anastomosis position of the LVAD outflow graft under 
the concentric graft case (red arrow $\mathrm{t}=100 \mathrm{~ms}$ ). Vorticity was eliminated by the helical flow in the eccentric graft case $(t=100 \mathrm{~ms})$. Reverse blood flow was observed in the concentric graft case (red arrow $\mathrm{t}=170 \mathrm{~ms}$ ), whereas evident helical flow was observed in the ascending aorta under the eccentric graft case.

\section{Discussion}

We established an FE-SPH-coupled model to investigate the dynamic, biomechanical. and hemodynamic differences resulting from two kinds of LVAD outflow graft anastomotic types, namely, the concentric and eccentric graft case. This study is the first to explore effect of LVAD outflow graft anastomotic type on the biomechanical response of the aortic valve. The hyperelastic material constitutive equation was used to describe the biomechanical property of the leaflet, and the fluid domain was described by a set of particles.

Aortic insufficiency that results from LVAD support is a worrisome complication in the aortic valve. Its progression causes LVAD-left ventricular (LV) recirculation and might require surgical intervention in the aortic valve [31]. According to a recent study [32], the pressure overload resulting from LVAD support is an important factor affecting aortic insufficiency. Many studies that aimed to reduce the pressure load in the aortic valve have been conducted. Reducing the LVAD support level [33] and changing the support level and left ventricular motion [34] are feasible methods to reduce the pressure load imposed on the aortic valve. However, both methods have disadvantages 
to the patients. Although the pressure load imposed on the aortic valve is reduced along with the reduction in the LVAD support level, the blood perfusion provided to vital organs is also reduced [35]. The change in support level would considerably affect the prognosis of the patient, especially for patients who suffer from severe left ventricular dysfunction. Regulating the support level synchronously with left ventricular motion also has some shortcomings to overcome before it could be applied in clinical practice. This method requires accurate monitoring of the left ventricular motion, which might increase the complexity of the control system [36]. In addition, the rapid change in the rotational speed of the LVAD might disturb its hemodynamic states and increase the risk of hemolysis and thrombosis. However, optimizing the LVAD outflow graft anastomotic type might be effective as an alternative method to reduce the pressure load on the aortic valve, providing a novel research idea for the improvement of the biomechanical states of the aortic valve.

Figure 3 B shows that during the opening phase, the axial hemodynamic force in the eccentric graft the case was slightly larger than that in the concentric graft case. By contrast, the axial hemodynamic force in the eccentric graft case was significantly smaller than that in the concentric graft case during the closing phase. This change provides many benefits for facilitating aortic valve opening during the opening phase and preventing pressure overload of the aortic valve during the closing phase. Given that the axial hemodynamic force is strongly related to transvalvular pressure gradient, the eccentric graft case significantly reduced the pressure at the aortic root, which could be attributed to the helical flow generated by the eccentric graft. In addition, axial 
hemodynamic oscillation was observed in the concentric graft case during the closing phase. This oscillation was named as the "water-hammer" effect, which is a pressure impact caused by the sudden stop of the blood supply. The pressure overload caused by this oscillation might be the reason for this phenomenon due to the aortic insufficiency occurring at the peak moment of the axial hemodynamic force oscillation. By contrast, the oscillation of the axial hemodynamic force was eliminated in the eccentric graft case. The helical flow generated by the eccentric graft was considered to be the main reason, because helical flow is beneficial to the maintenance of the direction of the blood flow, which could reduce the degree of axial hemodynamic force oscillation.

Figure $3 \mathrm{~A}$ shows that the closing time in the eccentric graft case was longer than in the concentric graft case. However, the velocity of the reverse blood flow under the eccentric graft case was significantly smaller than that under the concentric graft case

(Figure 8, $\mathrm{t}=100 \mathrm{~ms}$ ). This difference resulted from the pressure at the aortic root in the eccentric graft case being smaller than that in the concentric graft case.

\section{Limitation}

Some limitations of this study must be explained. First, the straight vessel model was used rather than the anatomic geometry of the aorta. This simplification might affect the motion, deformation, and stress distribution of the leaflet. However, this study aimed to compare the effect of anastomotic types on the biomechanical states of the aortic valve. The effect of simplifying the straight vessel on the aortic valve under both cases was the same for both types. Hence, the simplification would not interfere with the interpretation of the results. 
Second, the turbulence model was not used in this study due to the limitations of the software, which might affect the blood flow pattern in both cases. In the future, the turbulence model should be integrated into the FE-SPH-coupled model.

\section{Conclusion}

Comparative numerical studies were conducted to clarify the effect of LVAD outflow graft anastomotic types on the biomechanical states of the aortic valve, and the FE-SPH model was established. Two kinds of LVAD outflow graft anastomotic types, namely, the concentric and eccentric graft types, were designed. The outflow graft anastomotic type could significantly affect the biomechanical states of the aortic valve. During the opening phase, the motion, deformation, and biomechanical states of the leaflet were similar in the two cases. However, during the closing phase, the rapid closing time of the leaflet under the eccentric graft case $(40 \mathrm{~ms})$ was longer than that under the concentric graft case $(15 \mathrm{~ms})$. Moreover, during the opening phase, the axial hemodynamic force imposed on the leaflet in the eccentric graft case $(0.9 \mathrm{~N})$ was slightly larger than that in the concentric graft case $(0.3 \mathrm{~N})$. During the closing phase, the peak values of the axial hemodynamic force in the concentric graft case $(13 \mathrm{~N})$ was much larger than that in the eccentric graft case $(4.5 \mathrm{~N})$. Moreover, oscillation of the axial hemodynamic force on the leaflet was only observed in the concentric graft case. This oscillation might lead to aortic insufficiency. The eccentric graft could provide better biomechanical and hemodynamic states to the aortic valve than the concentric graft and could prevent aortic insufficiency. 


\section{Material and methods}

Geometric model of the aortic valve

In this study, a geometric model of the aortic valve was established in accordance with the data from Marom's work [28]. The model consisted of the leaflet and aortic sinus (Figures 1 A and B). The geometric sizes of the leaflet and aortic sinus were based on the data of Marom's study. The LVADs designed by Beijing University of Technology was used in the present study. The outflow cannula of LVADs composed of $12 \mathrm{~mm}$ polyester outflow graft. Hence, the diameter of the outflow graft was set at $12 \mathrm{~mm}$. In addition, the outflow cannula was modeled as a rigid cannula and was virtually added to the ascending aortic wall using FreeForm commercial software (Geomagic, USA). The model was named as either concentric or eccentric graft case according to the outflow graft anastomotic type. For the concentric graft case, the axis of LVAD outflow cannula was coplanar with the axis of the aorta (Figure 1 B). By contrast, the axis of LVAD outflow cannula was not coplanar with the axis of the aorta in the eccentric graft case. The distance between the axis of LVAD outflow cannula and that of the ascending aorta was set at $8 \mathrm{~mm}$ to generate evident helical blood flow (Figure 1 C).

\section{Smoothed Particle Hydrodynamics Theory}

SPH is an approach that utilizes a set of particles carrying physical properties to illustrate the blood flow pattern. For all particles, the changes in the motion, energy, and other physical properties were determined by the governing equations. Moreover, the numerical solution was obtained using the kernel interpolation technique $[25 ; 29]$ 
as shown in Equation 错误!未找到引用源。:

$$
A\left(r_{a}\right)=\sum m_{b} \frac{A_{b}}{\rho_{b}} W\left(r_{a}-r_{b}, h\right)
$$

where $A_{b}$ represents the physical property of particle $\mathrm{b}$ within the neighboring area of particle a at position $r_{b}$, h reflects the influential length of the kernel, $m_{b}$ represents the mass of particle $b$, and $\rho_{b}$ denotes the density of particle $b$. In this study, the cubic spline kernel $W(\cdot)$ was applied for interpolation. Based on this technique, the governing equations for the blood flow could be rewritten as the SPH form. The conservation of mass formulation can be obtained as follows:

$$
\frac{d \rho_{a}}{d t}=\sum m_{b} v_{a b} \cdot \nabla_{a} W_{a b}
$$

where $v_{a b}$ denotes the relative velocity between particles a and $\mathrm{b}$, and $\nabla_{a} W_{a b}$ represents the gradient of the kernel function. Similarly, the conservation of the momentum in SPH theory can be rewritten as follows:

$$
\frac{d v_{a}}{d t}=-\sum m_{b} \frac{P_{a}+P_{b}}{\rho_{a} \rho_{b}} \nabla_{a} W_{a b}+\sum m_{b} \frac{\left(\mu_{a}+\mu_{b}\right) v_{a b}}{\rho_{a} \rho_{b} r_{a b}^{2}} r_{a b} \cdot \nabla_{a} W_{a b}
$$

where $P$ and $\mu$ are the pressure and dynamic viscosity of the blood, respectively.

In SPH theory, the blood pressure is calculated based on the change in local blood density. In this work, the Us-Up equation of state Hugoniot form was used as follows:

$$
P=\frac{\rho_{0} c_{0}^{2} \eta}{(1-s \eta)^{2}}\left(1-\frac{\Gamma_{0} \eta}{1}\right)+\Gamma_{0} \rho_{0} E_{m}
$$

where $i_{0}$ represents the material constant; $c_{0}$ denotes the artificial speed of the sound;

is the nominal volumetric compressive strain, which is the function of the current density of blood flow; $\rho_{0}$ is the initial density of the blood; and $E_{m}$. reflects the internal energy of the unit mass. The blood was assumed as an incompressible, Newtonian fluid based on previous studies. Hence, in the present study, $\rho_{0}$ was set as 
$1050 \mathrm{~kg} / \mathrm{m}^{3}$, and the dynamic viscosity $\mu$ was set as $0.0035 \mathrm{~Pa} \cdot \mathrm{s}$. According to Mao's study [Mao et al. 2016], the speed of sound was much higher than the velocity of the blood in the aorta. Thus, the artificial speed of sound was set as $300 \mathrm{~m} / \mathrm{s}$ to mimic the incompressible property and reduce the computational time. Moreover, parameters $\Gamma_{0}$ and $\mathrm{s}$ were set as 0 in accordance with a previous study [24].

Constitutive equation of the aortic valve

According to a previous study [25], the biomechanical property of the aortic leaflets could be mimicked by the Odgen model. In the present study, the isotropic, hyperelastic incompressible, second-order Ogden model [22] was chosen to reflect the biomechanical property of the leaflets, as shown in Equation 错误!未找到引用源。：

$$
W=\sum_{i=1}^{N} \frac{2 \mu_{i}}{\alpha_{i}^{2}}\left(\bar{\lambda}_{1}^{\alpha_{i}}+\bar{\lambda}_{2}^{\alpha_{i}}+\bar{\lambda}_{3}^{\alpha_{i}}-3\right)
$$

where $W$ is the strain energy function, $\bar{\lambda}_{i}$ is the deviatoric principal stretches, and $\mu_{i}$ and $\alpha_{i}$ are the material parameters. According to Mao's work, $\alpha_{1}=67.74, \alpha_{2}=27.47$, $\mu_{1}=19.58 \mathrm{kPa}$, and $\mu_{2}=260.56 \mathrm{kPa}$. In addition, the biomechanical property of the vessel was assumed as a linear elastic model, in which Young's modulus was set as 2.0 $\mathrm{MPa}$, and the Poisson's ratio was set as 0.3 [30].

\section{Discretization of the FSI model}

To maintain an accurate simulation, we discretized the leaflets into 20,352 10-node modified quadratic tetrahedrons. To reduce the computational cost, the vessel, aortic sinus, and LVAD outflow cannula were set as discrete rigid parts. They were discretized into 671,445 A four-node linear tetrahedrons. The element sizes of the leaflets and vessel were similar to those in a previous study [6], in which the element size did not affect the accuracy of the simulation solution. For the blood 
domain, the mesh density was chosen as $0.7 \mathrm{~mm}$, which is consistent with the results obtained from a previous study [25]. Hence 1,387,166 one-node elements were created in the blood domain.

\section{FSI model setup and boundary condition}

The FSI simulation condition in this study was similar to that in Mao's study [24]. The upstream and downstream of the vessel were prolonged to eliminate the boundary effect on the aortic leaflet. The lengths of the upstream and downstream of the SPH particle were set as 150 min (Figure 1F) and $30 \mathrm{~mm}$, respectively. This length was consistent with the length of the ascending aorta of normal patients. Two rigid plates placed at the inlet and outlet of blood domain were used to apply the pressure and velocity boundary conditions on the blood domain, because these conditions could not be directly applied on the particles. The setting of the boundary condition assumed that the velocity at the blood inlet and outlet has flat profiles, as the particles near the plates are driven by the plates. Moreover, this setting is commonly used in conventional FSI simulation.

The nearly closed position of the leaflets was the initial stress-free state (Figure 2). Moreover, a velocity-pressure-combined boundary condition derived from a previous animal experiment was the boundary condition. In the animal experiment, the rotational speed of the LVAD was maintained constant during the entire cardiac cycle. Moreover, the rotational speed of the LVAD was set to periodically open the aortic valve, which was named as "partial support mode." The constant speed mode is the most widely used LVAD mode in clinical practice. Under this mode, the opening duration of the aortic valve under LVAD support is significantly reduced compared with that under normal conditions. In this study, the opening duration of the aortic valve was approximately $100 \mathrm{~ms}$. During systole, the time-varying uniform blood velocity measured in the 
previous animal experiment was applied at the inlet (ventricular and LVAD sides), whereas the corresponding aortic pressure waveform was applied at the outlet (Figure 1D). During diastole, the left ventricular pressure was applied at the inlet (ventricular side), the uniform time-varying blood velocity condition was still applied at the inlet of the model (LVAD side), and the aortic pressure data was still applied at the outlet. To reduce the computational cost, we calculated the pressure gradient between the ascending aorta and left ventricle obtained from the experimental animal data. The calculation results were used as the pressure boundary condition. Moreover, the beginning of the ejection phase of the left ventricle was the starting point of the SPH simulation. Three cardiac cycles were calculated to eliminate the influence of the initial condition. The results calculated at the third cardiac cycle were extracted to evaluate the motion and biomechanical states of the aortic valve. Simulation was performed on Intel Xeon (E2667) workstation with 32 cores, and $190 \mathrm{~h}$ was required for computation.

\section{Biomechanical analysis}

Two indicators, namely, radial position and axial hemodynamic force (AHF), were calculated to evaluate the different effects of the two LVAD outflow graft anastomotic types on the biomechanical states of the aortic valve.

Radial position (RP) was calculated to reflect the change in the position of the middle point of the free edge, which was closely related to the function of the aortic valve. The radial position was calculated as follows:

$$
\mathrm{RP}_{\mathrm{m}}(\mathrm{t})=r \overline{\left(\mathrm{x}_{\mathrm{m}}(\mathrm{t}) ; \mathrm{x}_{\mathrm{o}}\right)^{2}+\left(\mathrm{z}_{\mathrm{m}}(\mathrm{t}) ; \mathrm{z}_{\mathrm{o}}\right)^{2}}
$$

where $\mathrm{RP}_{\mathrm{m}}$ denotes the radial position of the middle point of the leaflet free edge, 
in which the unit is $\mathrm{mm}$; $\mathrm{t}$ represents the time; $\mathrm{x}_{\mathrm{m}}$ and $\mathrm{z}_{\mathrm{m}}$ are the values of $\mathrm{x}-$ and $\mathrm{z}$ axes, respectively; and $x_{0}$ and $z_{0}$ are the original points.

To evaluate the hemodynamic force on the leaflet imposed by the blood flow, we calculated the AHF as follows:

$$
\text { AHF }(t)=\frac{1}{S}_{s}{ }_{s} \mathrm{RF}_{\text {aorta }}(\mathrm{t}) \mathrm{ds} i \frac{1}{\mathrm{~S}}_{\mathrm{s}}^{\nu} \mathrm{RF}_{\text {ventricle }}(\mathrm{t}) \mathrm{ds}
$$

where $\mathrm{AHF}(\mathrm{t})$ denoteas the AHF at time point $t$; $\mathrm{RF}_{\text {aorta }}(\mathrm{t})$ and $\mathrm{RF}_{\text {ven tricle }}(\mathrm{t})$ are the reaction forces imposed on both sides of the leaflet; and s represents the area of the leaflet surface.

\section{Abbreviations}

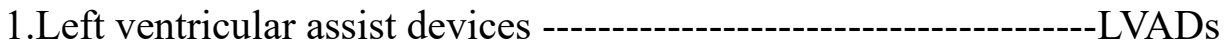

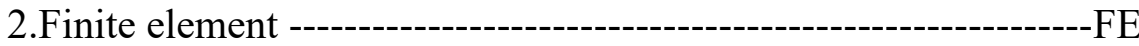

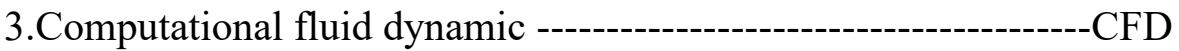

4.Fluid-structure interaction ----------------------------------------------FSI

5.Arbitrary Lagrangian-Eulerian ------------------------------------ALE

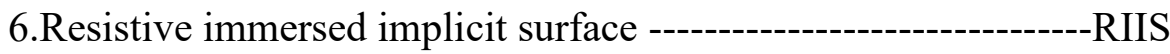

7.Smoothed particle hydrodynamic

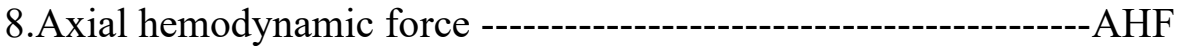

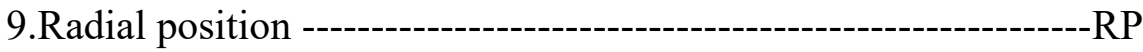

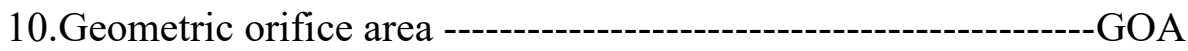




\section{References}

[1] Loebe M, Soltro E, Thohan V, et al. New Surgical Therapies for Heart Failure [J].Current Opinion in Cardiology, 2003, 18(3):194-8.

[2] Park S J, Milano CA, Tatooles AG, et al. Outcomes in Advanced Heart Failure Patients with Left Ventricular Assist Devices for Destination Therapy. Circ Heart Fail, 2012, 5:241-8.

[3] Jorde UP, Uriel N, Nahumi N, et al. Prevalence, significance, and management of aortic insufficiency in continuous flow left ventricular assist device recipients. Circ Heart Fail. 2014. 7(2):310-319.

[4] Gasparovic H, Kopjar T, Saeed D, et al. De Novo Aortic Regurgitation after Continuous-Flow Left Ventricular Assist Device Implantation. Ann Thorac Surg. 2017. 104(2):704-711.

[5] Stephens EH, Han J, Trawick EA, et al. Left-Ventricular Assist Device Impact on Aortic Valve Mechanics, Proteomics and Ultrastructure. Ann Thorac Surg. 2018. 105(2):572-580.

[6] Zhang Q, Gao B, Yu C. The Effects of Left Ventricular Assist Device Support Level on the Biomechanical States of Aortic Valve. Med Sci Monit. 2018. 24:2003-2017.

[7] Karmonik C, Partovi S, Loebe M, et al. Computational fluid dynamics in patients with continuousflow left ventricular assist device support show hemodynamic alterations in the ascending aorta. J Thorac Cardiovasc Surg. 2014. 147(4):1326-1333.e1.

[8] Zhang Y, Gao B, Yu C. The hemodynamic effects of the LVAD outflow cannula location on the thrombi distribution in the aorta: A primary numerical study. Comput Methods Programs Biomed. 2016. 133:217-227.

[9] Zhang Q, Gao B, Chang Y. Helical Flow Component of Left Ventricular Assist Devices (LVADs) Outflow Improves Aortic Hemodynamic States. Med Sci Monit. 2018. 24:869-879. 
[10] Shintani Y, Iino K, Yamamoto Y, et al. Analysis of Computational Fluid Dynamics and Particle Image Velocimetry Models of Distal-End Side-to-Side and End-to-Side Anastomoses for Coronary Artery Bypass Grafting in a Pulsatile Flow. Circ J. 2017. 82(1):110-117.

[11] Karmonik C, Partovi S, Loebe M, et al. Influence of LVAD cannula outflow tract location on hemodynamics in the ascending aorta: a patient-specific computational fluid dynamics approach. ASAIO J. 2012. 58(6):562-7.

[12] Sun A, Fan Y, Deng X, et al. Numerical comparative study on the hemodynamic performance of a new helical graft with noncircular cross section and SwirlGraft. Artif Organs. 2010. 34(1):22-7.

[13] Wen J, Zheng T, Jiang W, et al. A comparative study of helical-type and traditional-type artery bypass grafts: numerical simulation. ASAIO J. 2011. 57(5):399-406.

[14] Liu X, Wang L, Wang Z, et al. Bioinspired helical graft with taper to enhance helical flow. J Biomech. 2016. 49(15):3643-3650.

[15] Zakerzadeh R, Hsu MC, Sacks MS. Computational methods for the aortic heart valve and its replacements. Expert Rev Med Devices. 2017. 14(11):849-866.

[16] Marom G. Numerical Methods for Fluid-Structure Interaction Models of Aortic Valves [J]. Archives of Computational Methods in Engineering, 2015, 22(4):595-620.

[17] Chandra S, Rajamannan NM, Sucosky P. Computational assessment of bicuspid aortic valve wallshear stress: implications for calcific aortic valve disease. Biomech Model Mechanobiol. 2012. 11(7):1085-96.

[18] Wald S, Liberzon A, Avrahami I. A numerical study of the hemodynamic effect of the aortic valve on coronary flow. Biomech Model Mechanobiol. 2018, 17(2):319-338. 
[19] Bavo AM, Rocatello G, Iannaccone F, et al. Fluid-Structure Interaction Simulation of Prosthetic Aortic Valves: Comparison between Immersed Boundary and Arbitrary Lagrangian-Eulerian Techniques for the Mesh Representation. PLoS One. 2016. 11(4):e0154517.

[20] Fedele M, Faggiano E, Dedè L, et al. A patient-specific aortic valve model based on moving resistive immersed implicit surfaces. Biomech Model Mechanobiol. 2017. 16(5):1779-1803.

[21] Liu BGR, Liu MB. Smoothed Particle Hydrodynamics: A Meshfree Particle Method. New Jersey: World Scientific, 2003.

[22] SIMULIA. ABAQUS Analysis user’s Manual Dassault Systemes Simulia Corp. RI: Providence, 2010.

[23] Shahriari S, Maleki H, Hassan I, et al. Evaluation of shear stress accumulation on blood components in normal and dysfunctional bileaflet mechanical heart valves using smoothed particle hydrodynamics. J Biomech. 2012. 45(15):2637-44.

[24] Mao W, Caballero A, McKay R, et al. Fully-coupled fluid-structure interaction simulation of the aortic and mitral valves in a realistic 3D left ventricle model. PLoS One. 2017. 12(9):e0184729.

[25] Mao W, Li K, Sun W. Fluid-Structure Interaction Study of Transcatheter Aortic Valve Dynamics Using Smoothed Particle Hydrodynamics. Cardiovasc Eng Technol. 2016. 7(4):374-388.

[26] Qin Y, Wu J, Hu Q, et al. Computational evaluation of smoothed particle hydrodynamics for implementing blood flow modelling through CT reconstructed arteries. J Xray Sci Technol. 2017. 25(2):213-232.

[27] Yuan Q, X Ye, H Ma, et al. Fluid structure interaction study of bioprosthetic heart valve with FESPH method. Int. J. Adv. Comput. Technol. 5(8), 2013. 51.

[28] Marom G, Haj-Ali R, Raanani E, et al. A fluid-structure interaction model of the aortic valve with coaptation and compliant aortic root. Med Biol Eng Comput. 2012. 50(2):173-82. 
[29] Wang Z B, Chen R, Wang H, et al. An overview of smoothed particle hydrodynamics for simulating multiphase flow. Applied Mathematical Modelling, 2016, 40(23-24):9625-9655.

[30] Sturla F, Votta E, Stevanella M, et al: Impact of modeling fluid-structure interaction in the computational analysis of aortic root biomechanics. Med Eng Phys, 2013;35:1721-30.

[31] lizuka K, Nishinaka T, Naito N, et al. Left heart pressures can be the key to know the limitation of left ventricular assist device support against progression of aortic insufficiency. Journal of Artificial Organs, 2018:1-6.

[32] Tuzun E, Rutten M, Dat M, et al. Continuous-flow cardiac assistance: effects on aortic valve function in a mock loop. Journal of Surgical Research, 2011, 171(2):443.

[33] Silva J G D R E, Meyer A L, Eifert S, et al. Influence of aortic valve opening in patients with aortic insufficiency after left ventricular assist device implantation. European journal of cardio-thoracic surgery: official journal of the European Association for Cardio-thoracic Surgery, 2016, 49(3):784.

[34] Patel S R, Jorde U P. Creating adequate pulsatility with a continuous flow left ventricular assist device: just do it! Current Opinion in Cardiology, 2016, 31(3):329.

[35] Tuzun E, Pennings K, Van T S, et al. Assessment of aortic valve pressure overload and leaflet functions in an ex vivo beating heart loaded with a continuous flow cardiac assist device. Eur J Cardiothorac Surg, 2014, 45(2):377-83.

[36] Gao B, Chang Y, Gu K, et al. A pulsatile control algorithm of continuous-flow pump for heart recovery. Asaio Journal, 2012, 58(4):343-352. 


\section{Declarations}

\section{Ethics approval and consent to participate}

Not applicable

\section{Consent for publication}

Not applicable

\section{Availability of data and materials}

The datasets generated and/or analysed during the current study are available in the

PUBMED repository, DOI: 10.1016/j.jtcvs.2012.01.080

\section{Competing interests}

The authors declare that they have no competing interests.

\section{Funding}

Not applicable

\section{Authors' contributions}

ZMS FW YYZ and GLF carried out the concepts, design, definition of intellectual content, literature search. ZMS was a major contributor in writing the manuscript. 
LFZ YGD performed data acquisition, data analysis, geometric model and analyzed and interpreted the patient data, and performed the statistical analysis and carried out the study.

QW FYZ and HQW provided assistance for data acquisition and collected important background information.

All authors have read and approved the content of the manuscript.

\section{Acknowledgements}

Not applicable. 

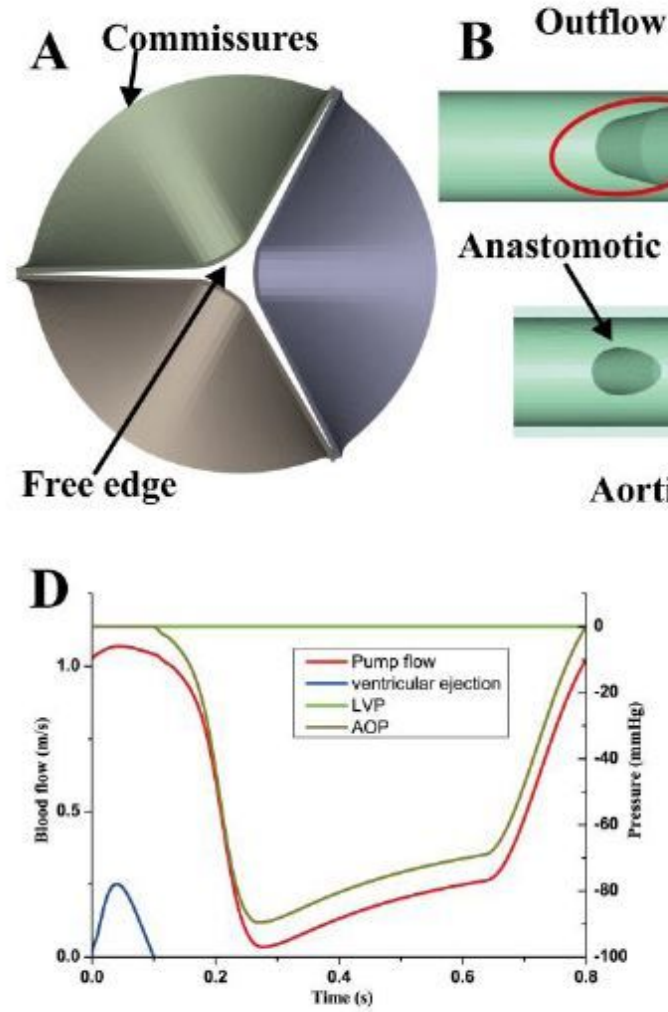

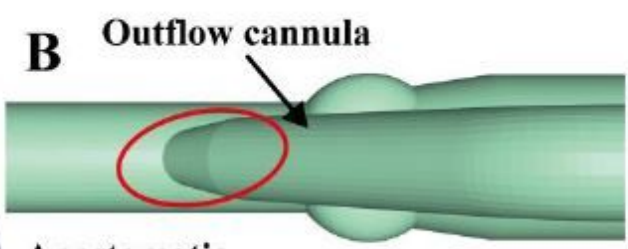

Anastomotic

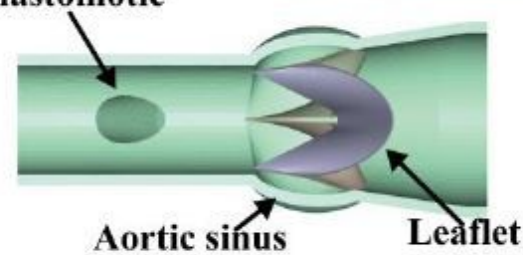

$\mathbf{E}$
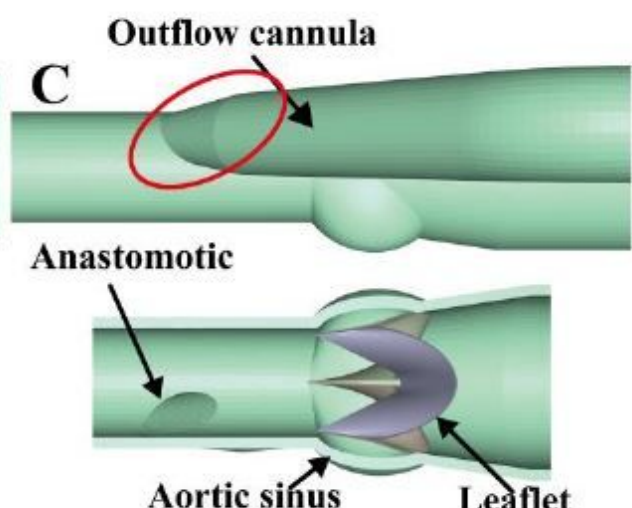

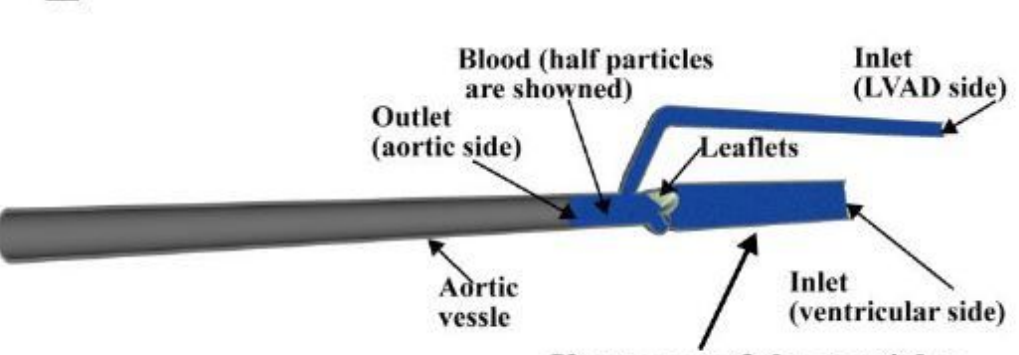

Upstream of the particles

\section{Figure 1}

(A) illustrated the geometric model of the concentric graft type. (B) Geometric models of the concentric and (C) eccentric graft types. (D) Boundary conditions applied to the model. (E) FE-SPH-coupled model. The model consisted of an aortic vessel, three leaflets, a rigid LVAD outflow cannula, and blood particles. Only half particles are shown in this figure.
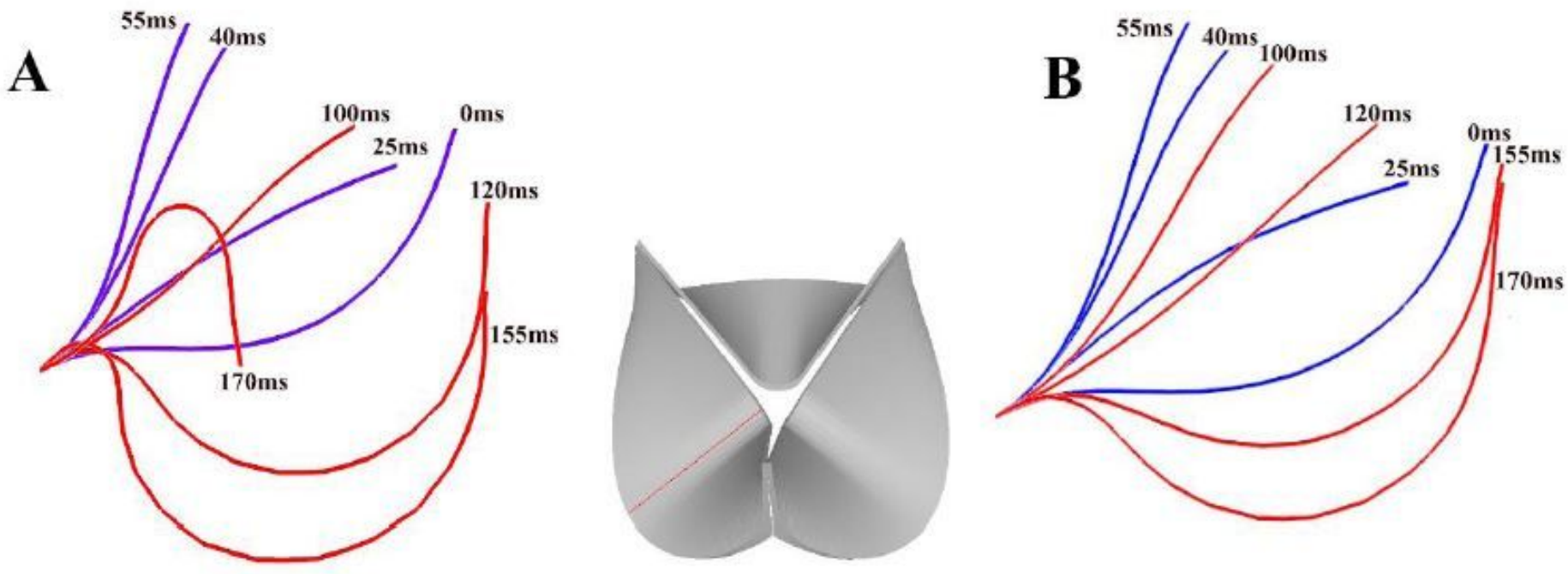
Figure 2

Time-dependent deformed shape of the middle line of the leaflet (the red line on the leaflet). Deformed shape of the leaflet under (A) concentric and (B) eccentric graft cases. The blue and red curves represented the deformed shape of the leaflet during the opening and closing phases, respectively.
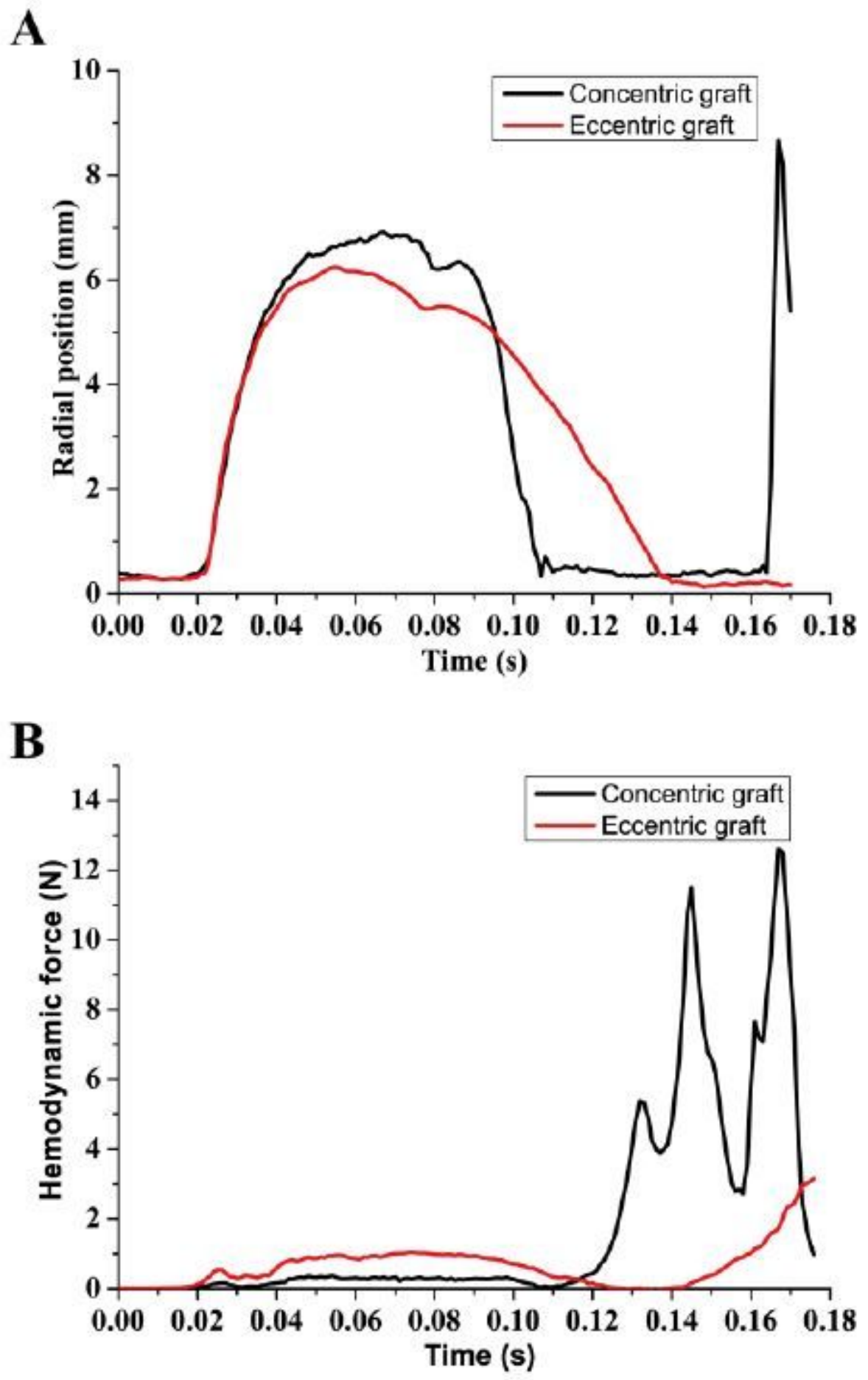

Figure 3 
Comparisons of radial position and axial hemodynamic force. (A) Time-dependent variation of the radial position of the middle point of the leaflet free edge under both cases. (B) Axial hemodynamic force imposed on the leaflet.

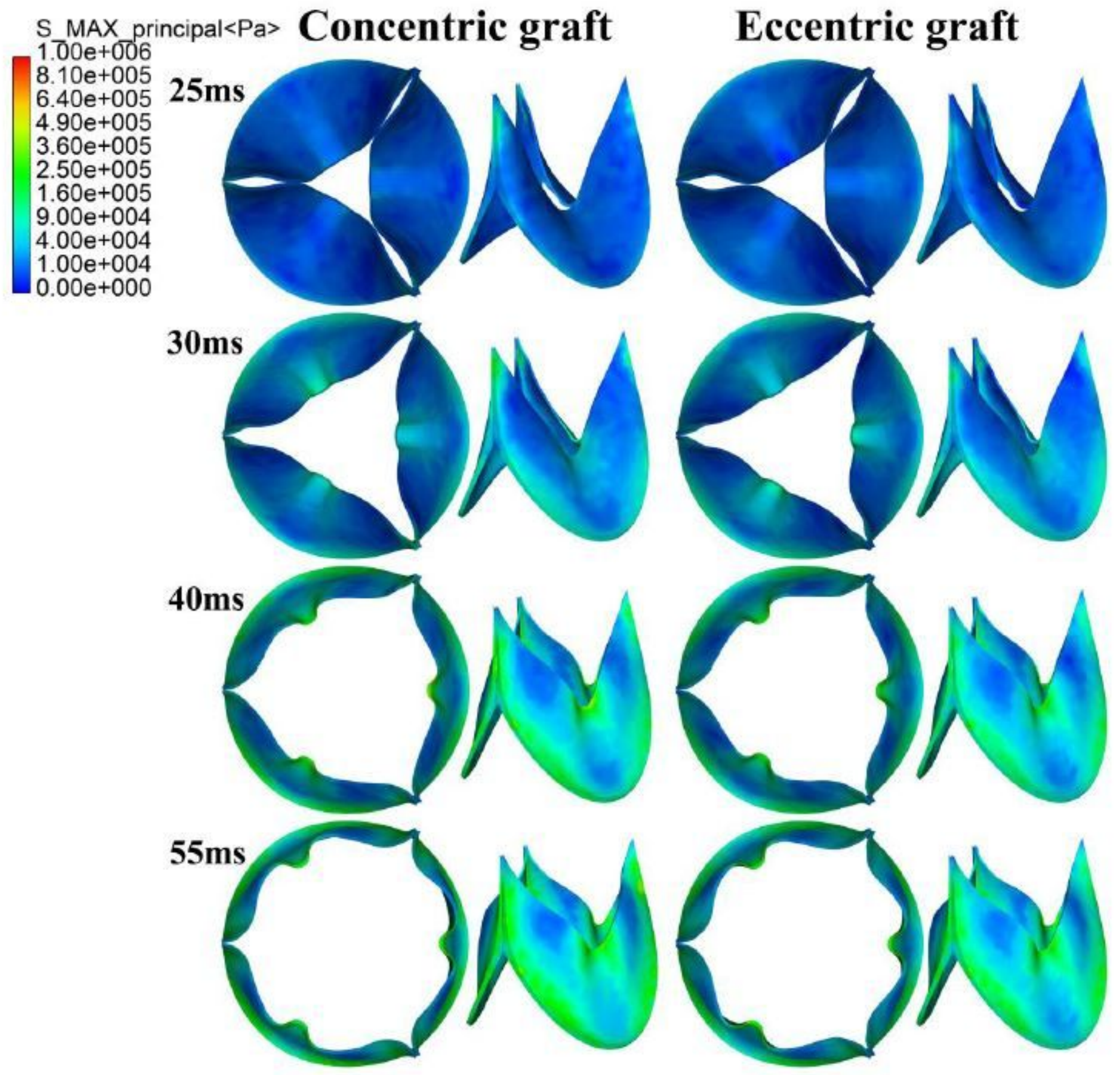

Figure 4

Contour curve of the maximum principal stress of leaflet during the systolic period. The scales were different in each instance. 


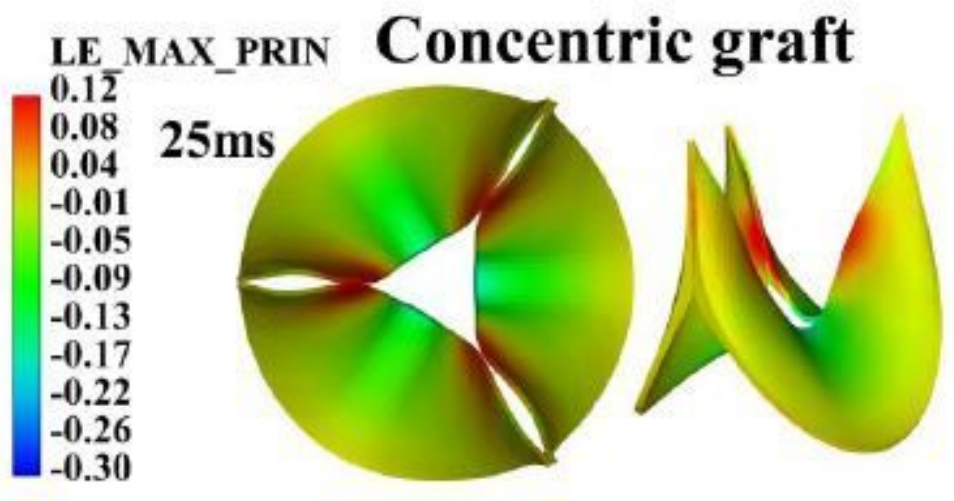

\section{Eccentric graft}
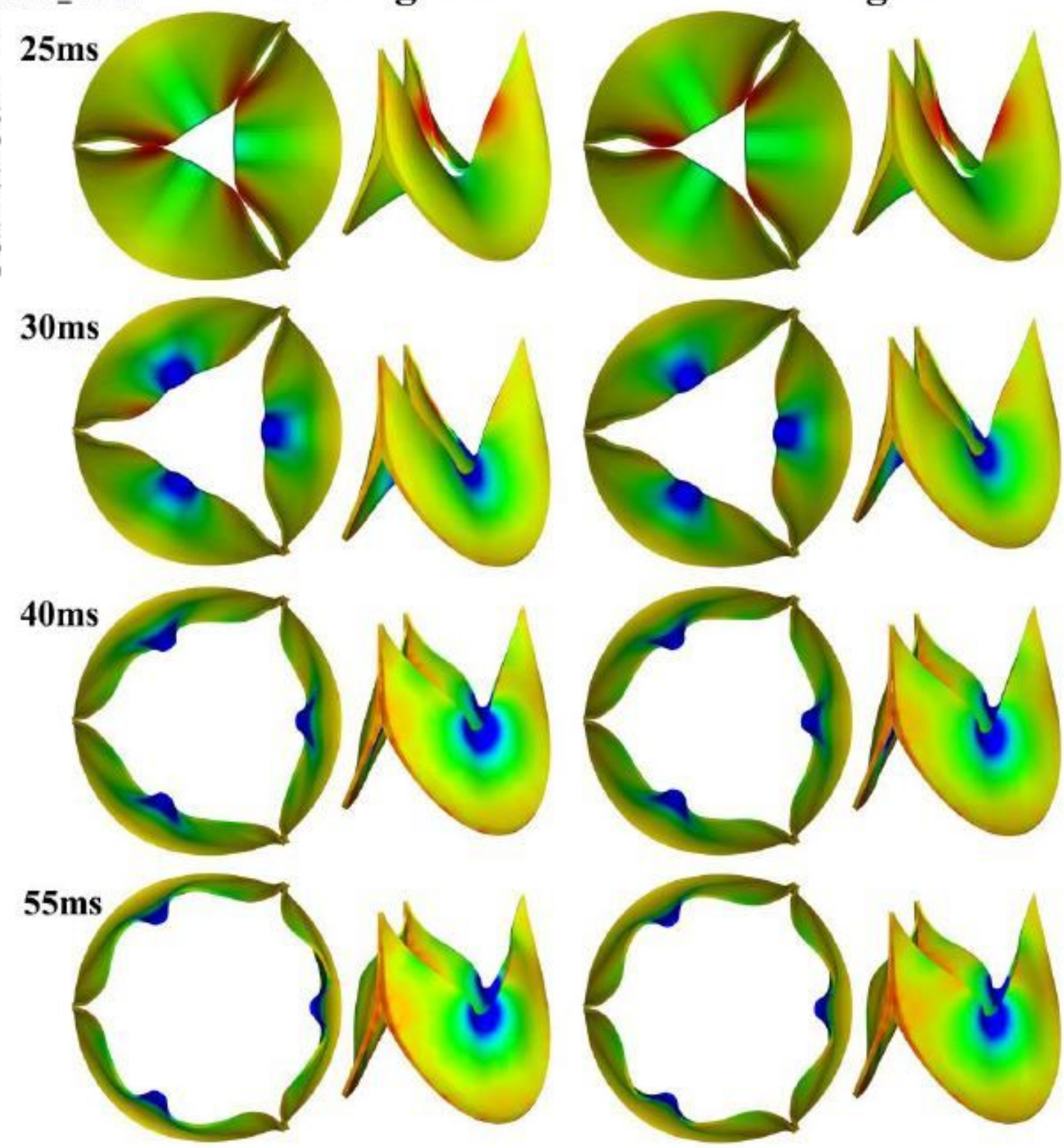

Figure 5

Contour curve of the true strain (LE) of leaflet during the systolic period. The scales were different in each instance. 
S MAX principal<Pa>

Concentric graft $1.00 \mathrm{e}+006$

$8.10 \mathrm{e}+005100 \mathrm{~ms}$

$6.40 e+005$

$4.90 \mathrm{e}+005$

3.60e+005

$2.50 \mathrm{e}+005$

$1.60 \mathrm{e}+005$

$9.00 \mathrm{e}+004$

$4.00 \mathrm{e}+004$

$1.00 \mathrm{e}+004$

$0.00 \mathrm{e}+000$
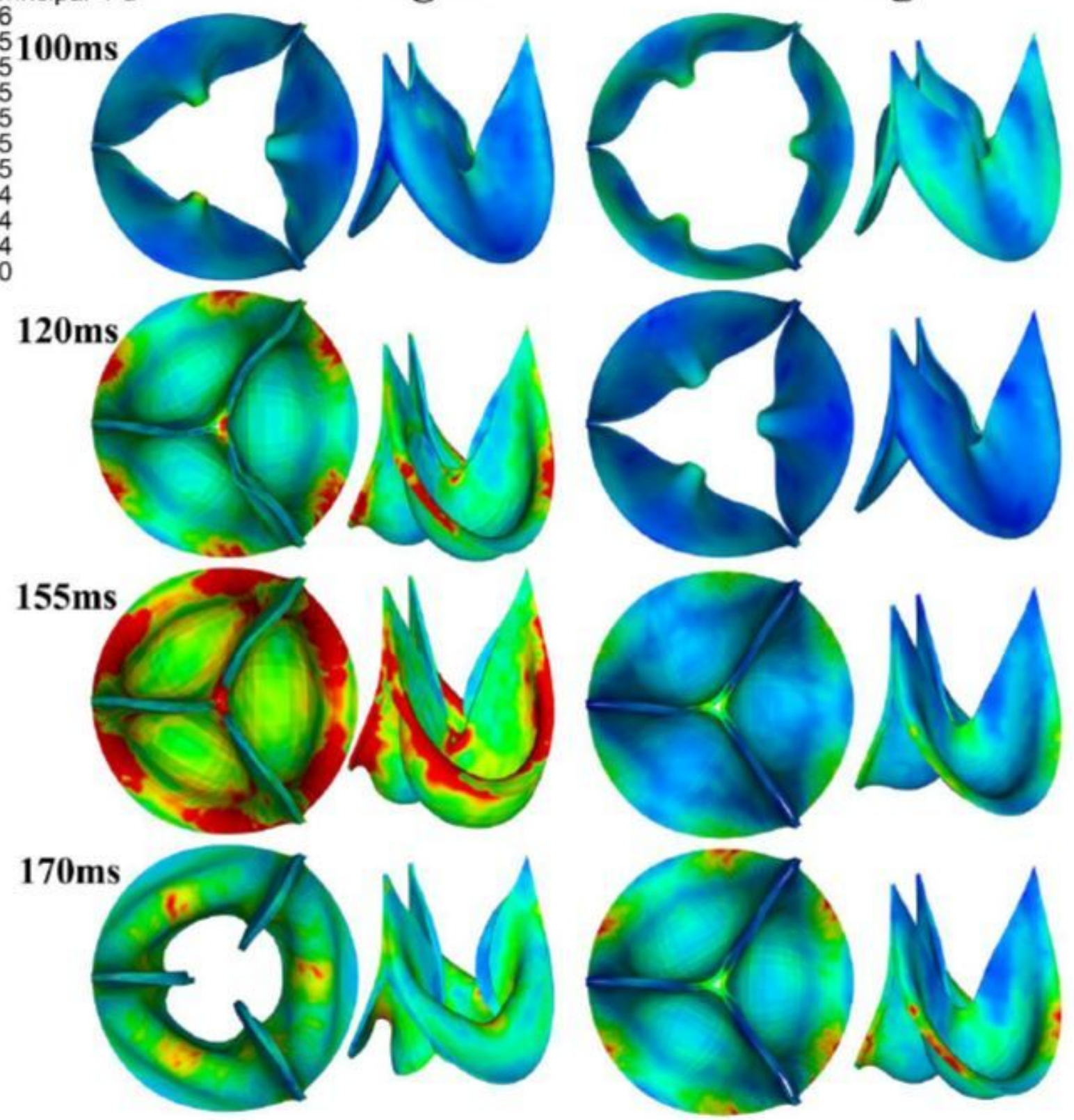

Figure 6

Contour curve of the stress of leaflet during the diastolic period. The scales were different in each instance. 


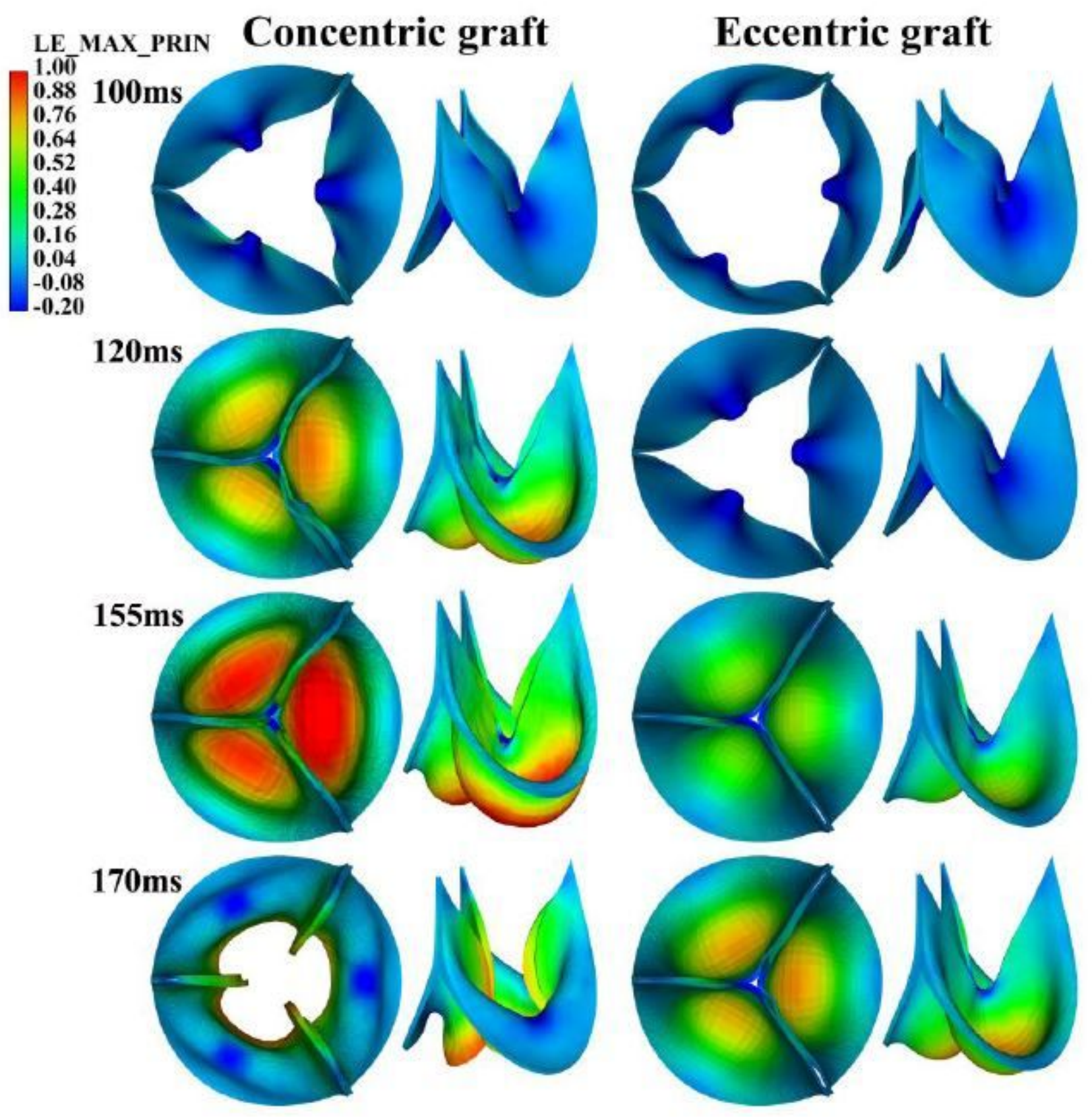

Figure 7

Contour curve of the true strain (LE) of leaflet during the diastolic period. The scales were different in each instance. 


\section{Concentric graft Eccentric graft}
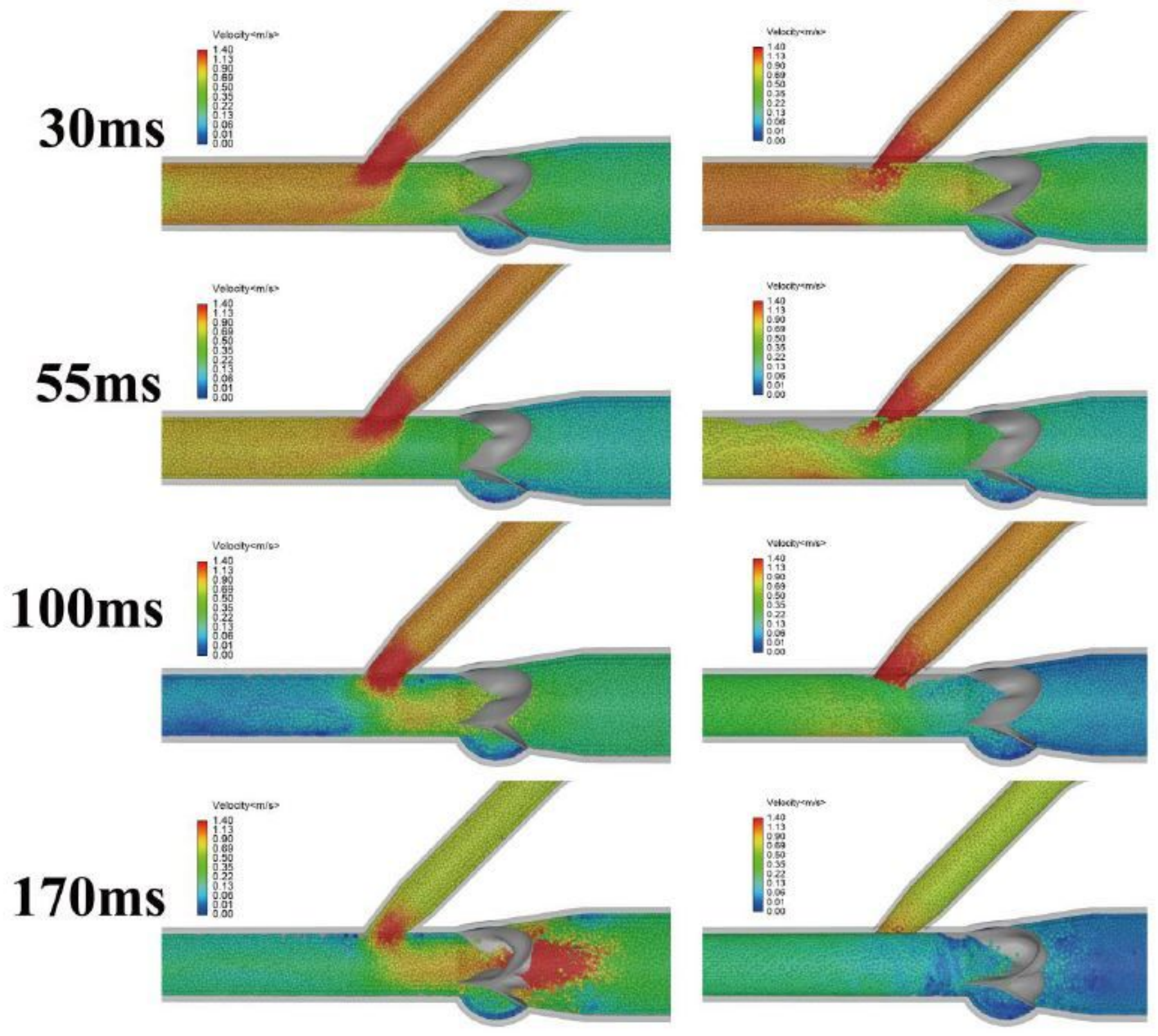

Figure 8

Blood flow velocity contour at different instances. 


\section{Concentric graft}
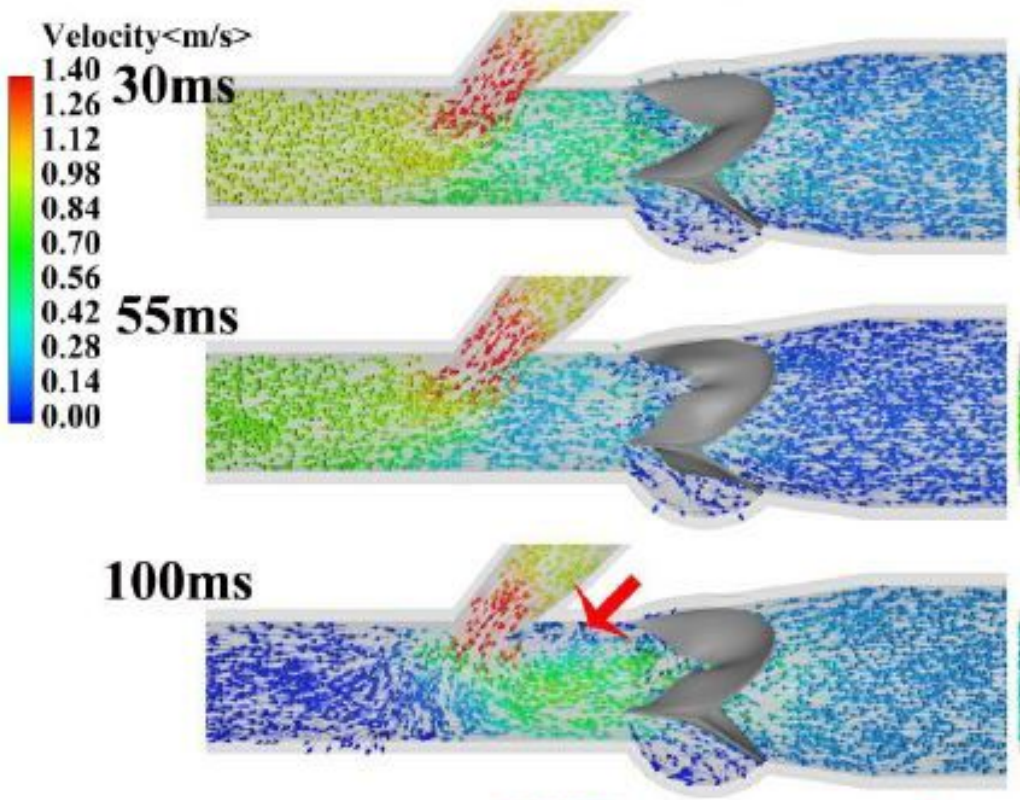

\section{$170 \mathrm{~ms}$}

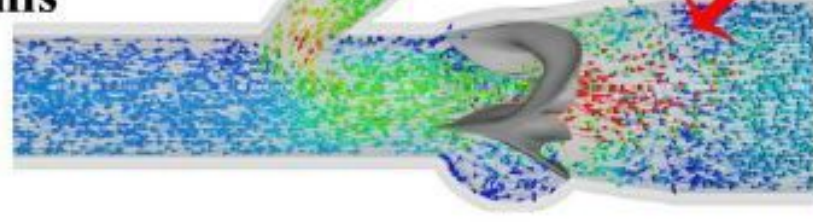

Eccentric graft
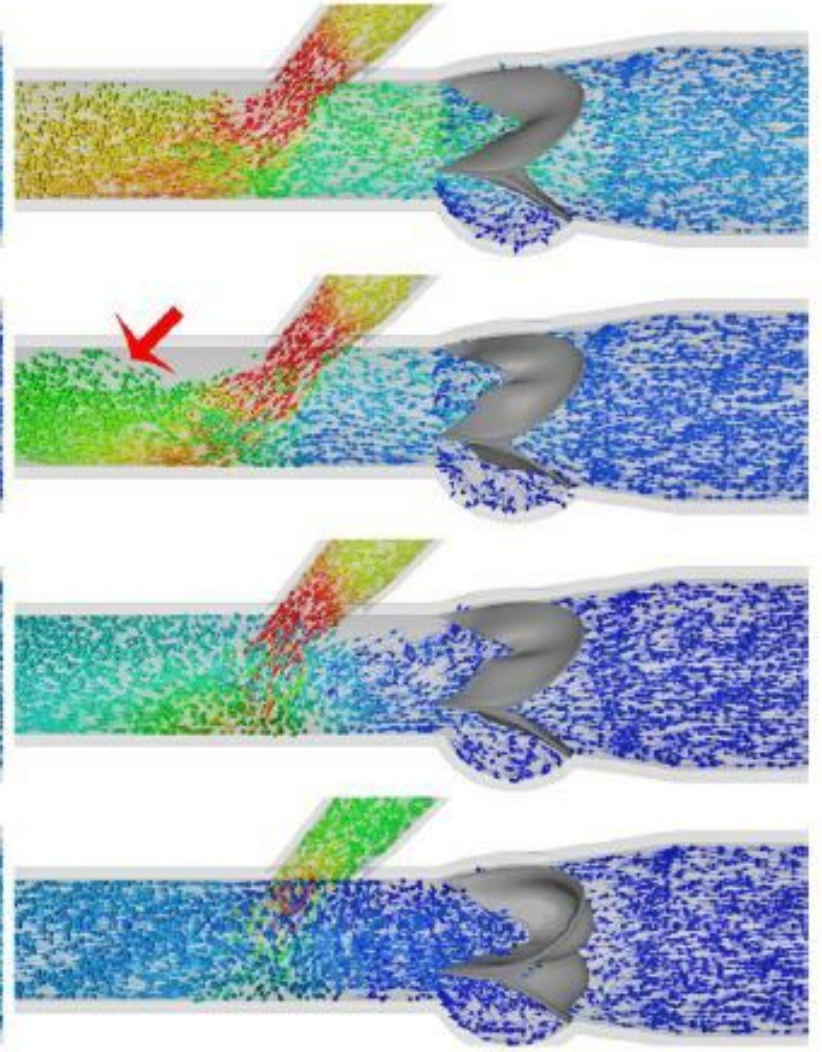

Figure 9

Blood flow velocity vector curve at different instances. 